\title{
Pluralismo jurídico y justicia indígena en Ecuador
}

\section{Legal pluralism and indigenous justice in Ecuador}

\author{
Cristian Ernesto Quiroz Castro
}

Universidad Internacional del Ecuador, Ecuador

Autor para correspondencia: crquirozca@uide.edu.ec

Fecha de recepción: 08 de noviembre de 2017 - Fecha de aceptación: 30 de noviembre de 2017

\section{Resumen}

El pluralismo jurídico y la justicia indígena son temas relativamente nuevos en nuestro país, pues, recién se los estudia con seriedad a partir de su incorporación en la Carta Magna expedida en el año 1998. Desde su inicio han generado polémica y conflictos sobre todo con la jurisdicción ordinaria. Este trabajo investigativo pretende dar al lector varias definiciones que le servirán de sustento para tener una aproximación a la justicia indígena, y sus particulares procedimientos utilizados para resolver sus conflictos internos, conforme a sus costumbres; y, para entender de mejor manera su cosmovisión. Así mismo, sin el ánimo de agotar el debate, se quiere poner de manifiesto que, es posible conciliar y armonizar la jurisdicción ordinaria con la jurisdicción indígena en un Estado constitucional de derechos y justicia como el nuestro.

Palabras clave: ancestrales; constitución; derecho consuetudinario; jurisdicción; nacionalidades

\begin{abstract}
Legal pluralism and indigenous justice are relatively new issues in our country, since they are only seriously studied after incorporating them in the Carta Magna issued in 1998. Since its inception they have generated controversy and conflicts, especially with the ordinary jurisdiction. This investigative work tries to give the reader several definitions that will serve as sustenance to have an approximation to the indigenous justice, and its particular procedures used to solve their internal conflicts, according to their customs; and to better understand their worldview. Likewise, without wishing to exhaust the debate, we want to show that it is possible to reconcile and harmonize ordinary jurisdiction with indigenous jurisdiction in a constitutional state of rights and justice such as ours.
\end{abstract}

Key words: ancestral; constitution; customary law; jurisdiction; nationalities 


\section{Introducción}

En el Ecuador de acuerdo al último censo poblacional (INEC, 2017) efectuado en el año 2010, el 7\% de la población es indígena. No obstante, recién a partir de la expedición de la Constitución Política de la República en el año 1998, el Estado ecuatoriano, por un lado, se autodefine como pluricultural y multiétnico, esto significa que, la sociedad ecuatoriana acepta la diversidad de pueblos, culturas y nacionalidades indígenas que habitan en su territorio; y, por otro, se reconoce la jurisdicción indígena como mecanismo de solución de sus conflictos internos, conforme a sus costumbres y derecho consuetudinario ${ }^{1}$. Con la promulgación y publicación de la Constitución de la República en octubre de $2008^{2}$, se ratificaron y ampliaron los derechos de los pueblos ancestrales, principalmente de los pueblos y nacionalidades indígenas. Es decir, en el Ecuador a partir del año 1998 coexisten dos sistemas jurisdiccionales, lo que los doctrinarios llaman "pluralismo jurídico", que a decir de Eliza Cruz significa que:

El pluralismo jurídico constituye uno de los conceptos centrales tanto de la antropología como de la sociología jurídica, y se refiere a la coexistencia de sistemas jurídicos diversos dentro de un mismo campo social, lo cual cuestiona la visión etnocéntrica del derecho occidental, que ha sido construida asignándole el papel de único y legítimo referente del derecho por el positivismo jurídico, concepción ésta que vino a respaldar y consolidar la empresa colonial. El cuestionamiento a la centralidad del derecho estatal ha sido uno de los focos de atención de los estudios antropológicos del derecho y de la sociología jurídica, interesados en dar cuenta de la vigencia de otros sistemas jurídicos dentro de los estados nacionales. (Cruz, 2008, p.31).

Ahora bien, la primera interrogante que deberíamos plantearnos es ¿qué es el derecho indígena? La dirigente indígena Lourdes Tibán Guala, ex Asambleísta Nacional, sobre esta particular señala:

Para nosotros los indios, el derecho es un derecho vivo, dinámico, no escrito, el cual a través de su conjunto de normas regula los más diversos aspectos y conductas del convivir comunitario. A diferencia de lo que sucede con la legislación oficial, la legislación indígena es conocida por todo el pueblo, es decir, que existe una socialización en el conocimiento del sistema legal, una participación directa en la administración de justicia, en los sistemas de rehabilitación, que garantiza el convivir armónico. (...) Derecho indígena, es el conjunto de normas y leyes de los pueblos y nacionalidades indígenas para defender y administrar nuestras tierras y territorios, para mantener la paz y el orden en nuestras comunidades y pueblos. (Tibán, 2001, p. 88 y 89; INDESIC, 2001).

En este sentido, Miguel Hernández Terán, citando al dirigente indígena Carlos Pérez Guartambel, agrega:

Derecho indígena es el conjunto de preceptos y normas milenarias afloradas en las comunidades originarias, guiadas por una concepción cosmogónica filosófica presentes en la memoria colectiva que han sido generacionalmente transmitidos oralmente y dinamizados por

\footnotetext{
${ }^{1}$ Constitución Política de la República del Ecuador, artículo 191.

${ }^{2}$ Constitución de la República del Ecuador, artículo 1 y s.s.
} 
los pueblos de hoy, reconocidos y aceptados por adhesión, como garantía de un equilibrio social. (Pérez, como se citó en Hernández, 2011, p. 12 y 13).

Es decir, el Derecho indígena constituye un conjunto de valores y principios que forman parte del individuo, de la naturaleza y de su espíritu, cuya sumatoria constituye su cosmovisión. Este Derecho tiene una función restaurativa y no sancionatoria (como el derecho occidental), esto significa que, el indígena convive en armonía con su entorno (personas y naturaleza); sin embargo, cuando aquella armonía se ve afectada o alterada por uno o varios individuos del colectivo, se activa el Derecho indígena con el sólo propósito de restaurar el equilibrio, de volver las cosas a su estado pacífico habitual, a través de sus propios procedimientos o derecho consuetudinario. Vale la pena destacar que cada nacionalidad o pueblo indígena tiene sus particulares mecanismos para resolución de conflictos, pues, pese a ser todos de la misma raza (indígena), cada comunidad posee sus propias costumbres y tradiciones.

\section{Metodología}

En el desarrollo de este artículo científico utilizaremos el método analítico-descriptivo, que nos permitirá entender en forma sencilla la jurisdicción e instituciones indígenas, como, por ejemplo, la justicia restaurativa, la oralidad de sus procedimientos, la participación de la comunidad, etc. El método hermenéutico, nos ayudará a interpretar las diferentes corrientes doctrinarias elaboradas por juristas nacionales e internacionales, así como también, la jurisprudencia dictada por diversos jueces en materia constitucional. Finalmente, el método histórico nos servirá para estudiar el derecho consuetudinario indígena, a partir de los primeros registros de los que se tiene conocimiento, esto brindará al lector un amplio conocimiento de la celeridad y eficiencia del sistema jurisdiccional indígena, además, de la participación activa de los comuneros en la toma de decisiones y, la posterior reinserción en el colectivo del infractor y su familia.

\section{Desarrollo}

El Ecuador históricamente ha sido habitado por culturas y pueblos indígenas (Incas), quienes durante milenios han resuelto sus conflictos conforme a sus costumbres y tradiciones, situación que les ha permitido vivir en un estado de paz dentro de sus organizaciones o colectivos; y, en armonía con su entorno natural o Pacha mama.

En este sentido, el jurista argentino Ricardo Rabinovich-Berkman manifiesta:

Como viéramos y como es obvio, una de las cuestiones más peculiares que presentaba América era la presencia de las comunidades aborígenes. Éstas eran innumerables, y cada una tenía sus propias construcciones jurídicas, sin menoscabo de aquellas que se aplicaban sobre etnias diversas, como por ejemplo las normas generales inherentes al Tawantinsuyo en Sudamérica o al Anáhuac en México. (RabonovichBerkman, 2016, p.390).

Sin embargo, con la llegada de los españoles al continente americano, esa paz y armonía entró en conflicto con las costumbres, ideologías y normas jurídicas provenientes de Europa e 
impuestas a través de la violencia y la fuerza. Sobre este aspecto, el Doctor José Reig Satorres agrega:

Han transcurrido cinco siglos, y la noción y práctica de los derechos humanos hay que entenderla acorde con aquel tiempo. Aunque la cultura humana, y racionalización del pensamiento, aceleró sus pasos desde el Renacimiento a principios del siglo XVI, en Occidente se da un agudo individualismo, con gran afán de poder y enriquecimiento que fácilmente desemboca en egoísmo. Si a esto unimos el sentido de aventura que tienen las tierras americanas; el verse superiores a los naturales; verse ante tantas riquezas vírgenes; extensiones territoriales desconcertantes y una naturaleza tan vigorosa, hace que en conjunto se multipliquen más los problemas. (Reig y Larrea, 2000, p.138).

Los historiadores y juristas coinciden en que las costumbres y tradiciones de los pueblos aborígenes americanos fueron mantenidas por los españoles (Reig y Larrea, 2000), debido principalmente, a la experiencia observada en el imperio romano, pues, una estrategia que utilizaron la mayoría de césares romanos para apaciguar los ánimos de los pueblos conquistados y poder someterlos, evitando futuras sublevaciones, fue la de conservar su derecho consuetudinario, al que denominaron derecho común.

Ahora bien, este derecho consuetudinario de los pueblos aborígenes con el que se encontraron los españoles, es el que hoy en día se conoce con el nombre de Derecho indígena, que consiste en la facultad que tienen los indígenas para autogobernarse; para ser consultados sobre políticas públicas a ser aplicadas dentro de sus territorios; para aplicar sus costumbres en la resolución de conflictos, etc. Así lo reconoce Rafael Santa María al expresar:

Un elemento adicional para tener en cuenta, que no niega la diversidad de testimonios, la variedad de puntos de vista y la heterogeneidad de los documentos; es que todas estas fuentes conducen de manera objetiva, a evidenciar la existencia de un derecho prehispano. Negar esta evidencia, es como desconocer la existencia de un sistema económico, social y político de los Incas, y en última instancia es desconocer la misma historia (Santa maría, 2012, p.174 y 175).

Vale la pena recordar que los Incas no conocieron la escritura, por lo que, los conocimientos se transmitían de generación en generación en forma oral (Rosillo, 2012, p.153 y ss.). No se debe confundir el Derecho indígena con el derecho indiano. Respecto del segundo Jorge Basadre manifiesta: “(...) y el derecho español aplicado a América, es decir el Derecho indiano, procuró en mucho copiar las instituciones propias de los indios, como evidencian las leyes sobre tributos, mita, comunidades, etc.” (Basadre, 1984, p.66).

De lo expuesto, a manera de primera conclusión, podemos destacar, en general, que el Derecho indígena es anterior a la Colonia y a la posterior transpolación del Derecho europeo; y, del Derecho castellano, en particular; desde la consolidación de la Colonia Española, siempre se reconocieron sus mecanismos jurisdiccionales; sus conflictos se resuelven a través de procesos sumarios y orales, teniendo en consideración su identidad cultural.

Empero, el Derecho indígena luego de la proclamación de la Independencia y de la conformación de la República del Ecuador en el año 1830, fue perdiendo vitalidad o, siendo más 
precisos, fue siendo relegado hasta el punto de ser excluido del ordenamiento jurídico. Esto se debió principalmente, a la hegemonía en el poder estatal que ejercieron las clases dominantes de raza blanca-mestiza (desde 1830 hasta la actualidad), quienes se dedicaron a legislar y reconocer derechos en forma exclusiva y excluyente para sí mismos, desconociendo derechos de otros grupos étnicos que integran el Ecuador, como, por ejemplo, los afroecuatorianos, los montubios y los indígenas. Al respecto, Elías Díaz agrega:

(...) implicó aceptar que históricamente a los indígenas, entre otros grupos, se los discriminó y excluyó también materialmente de bienes para el desarrollo, al punto que se puso en peligro su vida biológica, tanto como sus sistemas religiosos, su autonomía para castigar internamente las acciones antijurídicas, su organización social, sus lenguas. Fue tan grave el peligro, pensándolos y tratándolos como inferiores, excluidos de los presupuestos nacionales y asilados, que sólo un trato especial, un trato preferencial que contribuyera a recuperar su condición de pueblos distintos, con culturas alternas podría lograr un día la igualdad real y no formal de estos sujetos. (Díaz, 1985, p.74).

Sin embargo, el movimiento indígena por su propia iniciativa fue teniendo mayor protagonismo en el país, sobre todo en el orden político, es así que en 1926 se constituye la Federación Ecuatoriana de indios (FEI), tuvo participación en las movilizaciones campesinas de las haciendas, para que los campesinos e indígenas accedieran a la tierra, a través del huasipungo. En el año 1986 constituyen la Confederación de Nacionalidades Indígenas del Ecuador (CONAIE), agrupación de carácter nacional que mediante su lucha ha conseguido importantes reivindicaciones a favor de los derechos de los indígenas. Pero es sin lugar a dudas a inicios de los años 1990 cuando el movimiento indígena se afianza. En este sentido, el dirigente indígena Luis Macas enseña:

la actividad organizativa del movimiento indígena se centra en la elaboración de su propuesta política y la construcción de las estrategias y mecanismos de lucha, en perspectiva de su unidad interna y la ampliación del espacio de lucha en alianza con otros sectores, hacia la redefinición de la estructura institucional y de la sociedad. En este contexto se explica el planteamiento y la realización histórica del Levantamiento de mayo y junio de 1990, el acontecimiento más grande en los últimos años del siglo y milenio anterior. (Macas. 2002).

Finalmente, en el año 1995 crean el Movimiento de Unidad Plurinacional Pachakutik Nuevo País, organización que constituye el brazo político de la CONAIE, con la que han obtenido algunos triunfos electorales, sobre todo, en candidaturas para ocupar dignidades en los Gobiernos Autónomos Descentralizados (GADS), esto es, Prefecturas, Alcaldías y Juntas Parroquiales, así como también, algunas curules en la Asamblea Nacional.

Es decir, por más de 500 años los indígenas han resistido la opresión, exclusión y discriminación ejercida por los grupos dominantes blanco-mestizos, sin embargo, han logrado mantener y conservar de forma casi intacta, sus culturas y tradiciones, particularmente, las relacionadas con la forma de concebir al mundo; de tratar a sus semejantes; de la administración de la tierra y del agua; y, de la administración de justicia. 
El corolario de la lucha y resistencia indígena se evidencia en la elaboración de la Constitución Política de la República, expedida en el año 1998, que incorpora por primera vez en nuestro país el reconocimiento de varios derechos indígenas, partiendo desde la concepción del nuevo Estado multicultural y pluriétnico, es decir, el Ecuador reconoce su pluralidad étnica y cultural, sin caer en la secesión, pues, se proclama la unidad en la diversidad del territorio ecuatoriano. Asimismo, se establece y garantiza la autoridad jurisdiccional de los pueblos y nacionalidades indígenas para resolver sus conflictos, siempre que no contraríen a la Constitución y los Instrumentos Internacionales sobre Derecho Humanos.

La reivindicación de los derechos indígenas fue confirmada y ampliada por la Constitución de la República, promulgada, publicada y ratificada mediante referéndum en el año 2008. En este sentido, el constituyente definió al Ecuador como un Estado plurinacional, debido a que dentro de su territorio coexisten varias nacionalidades y etnias, como los indígenas, afroecuatorianos, montubios, además de la población hegemónica, situación que ha permitido un profundo debate desde la perspectiva intercultural, que converge en un modelo democrático incluyente, donde prima el respeto y reconocimiento de los derechos de los grupos sociales minoritarios. (Masapanta, 2015, p.6.).

Al respecto, Alberto Acosta destaca:

(...) la declaratoria del estado Plurinacional por parte de la Asamblea Constituyente, en Montecristi, representa, por un lado, un acto de resarcimiento histórico para los pueblos y nacionalidades indígenas. Y, por otro lado, es simultáneamente una oportunidad para que nuestra sociedad aprenda de los otros, asumiendo un compromiso de convivencia democrática y equitativa, en el que la armonía debe ser la marca de las relaciones de los seres humanos entre sí, y de éstos con la Naturaleza (...) el reto es concebir el principio de la plurinacionalidad como la sustancia fundamental en el ejercicio de la democracia incluyente, pero sobre todo como propuesta de vida diverso y en mayor armonía y cercanía con la Naturaleza; la plurinacionalidad, entonces, no puede dejar de ser leída junto con otras definiciones que tienen que ver con el territorio y con el manejo de las riquezas naturales. (Acosta, 2009, p.7 y ss.).

Dentro de este contexto, el Estado ecuatoriano, a través de la Constitución de la República, en su artículo 57 reconoce y garantiza a los pueblos y nacionalidades indígenas, entre otros, los siguientes derechos colectivos:

9. Conservar y desarrollar sus propias formas de convivencia y organización social, y de generación y ejercicio de la autoridad, en sus territorios legalmente reconocidos y tierras comunitarias de posesión ancestral.

10. Crear, desarrollar, aplicar y practicar su derecho propio o consuetudinario, que no podrá vulnerar derechos constitucionales, en particular de las mujeres, niñas, niños y adolescentes. (Constitución de la República, 2008, art.57).

Así mismo, el artículo 171 de la misma Carta Magna prescribe: 
Las autoridades de las comunidades, pueblos y nacionalidades indígenas ejercerán funciones jurisdiccionales, con base en sus tradiciones ancestrales y su derecho propio, dentro de su ámbito territorial, con garantía de participación y decisión de las mujeres. Las autoridades aplicarán normas y procedimientos propios para la solución de sus conflictos internos, y que no sean contrarios a la Constitución y a los derechos humanos reconocidos en instrumentos internacionales.

El Estado garantizará que las decisiones de la jurisdicción indígena sean respetadas por las instituciones y autoridades públicas. Dichas decisiones estarán sujetas al control de constitucionalidad. La ley establecerá los mecanismos de coordinación y cooperación entre la jurisdicción indígena y la jurisdicción ordinaria. (Constitución de la República, 2008, art.171).

Es decir, la justicia indígena, en lo que atañe al ejercicio, desarrollo y aplicación de su derecho consuetudinario, tiene como único límite los preceptos constitucionales y los instrumentos internacionales sobre derechos humanos, situación que es debatible, pero que, para efectos de este trabajo, no nos corresponde analizar.

Ahora bien, como lo señalamos en líneas anteriores, cada pueblo y nacionalidad indígena tiene sus propias costumbres y tradiciones que los diferencian de los demás o, que, en su defecto, los individualiza como comunidad, verbigracia, idioma, vestimenta, alimentación, territorio, métodos y procedimientos para la resolución de conflictos, etc. En Ecuador de acuerdo a cifras proporcionadas por el Consejo de Desarrollo de las Nacionalidades y Pueblos Indígenas del Ecuador (SIDENPE), existen 13 nacionalidades indígenas con presencia en las 3 regiones, esto es, Costa, Sierra y Oriente. Cada nacionalidad mantiene su lengua y culturas propias. (SIDENPE. 2017).

Adicionalmente, existen pueblos no contactados como los Tagaeri, los Taromenane y los Oñamenane, de los cuales no se tiene mayor referencia, sólo se sabe que habitan en la profundidad de la selva amazónica, particularmente, en las provincias de Orellana y Pastaza.

A las diferencias entre pueblos y nacionalidades indígenas anotadas, debemos sumar las relacionadas con los métodos para la resolución de sus conflictos, o lo que es lo mismo, con sus procedimientos jurisdiccionales. En efecto, tenemos dos tipos de organización jurisdiccional, por un lado, tenemos el Cabildo comunal; y, por otro, el Cabildo comunitario. El primero se encuentra contenido en la Constitución de la República y la Ley de Organización y Régimen de las Comunas, donde se establece el "Cabildo" como órgano oficial y representativo de la comuna, integrado por cinco miembros, quienes ejercerán las funciones de presidente, vicepresidente, tesorero, síndico y secretario. Entre las principales atribuciones del Cabildo está la de crear, desarrollar, aplicar y practicar su derecho propio o consuetudinario, que no podrá vulnerar derechos constitucionales, en particular de las mujeres, niñas, niños y adolescentes. La Asamblea es la máxima autoridad del Cabildo, que se encuentra conformada por todos los comuneros mayores de 18 años de edad, de esta forma los comuneros ejercen su autoridad a través de la democracia participativa, pues, son ellos (Asamblea) la que resuelve los conflictos que se generan en cada Comuna. 
El segundo, denominado Cabildo comunitario, tiene sustento en las normas constitucionales, su organización, funcionamiento y prácticas jurisdiccionales dependen de la cultura e idiosincrasia particular de cada pueblo, es decir, cada comunidad indígena establece su propio procedimiento para el juzgamiento de infracciones cometidas en sus territorios.

Finalmente, vale la pena destacar que la Corte Constitucional del Ecuador, el 30 de julio de 2014, dentro del caso $\mathrm{N}^{\circ}$ 0731-10-EP denominado caso "La Cocha", dictó la sentencia $\mathrm{N}^{\circ} 113-14-S E P-C C$. En el fallo, los jueces constitucionales hacen un análisis exhaustivo de la cosmovisión del pueblo de la Cocha, para ello, incluso contrataron a 2 antropólogos del más alto nivel, quiénes son recurrentemente citados a lo largo de la mencionada sentencia, estableciendo en su pericia criterios como el siguiente:

"(...) frente a un desfase en la armonía de la comunidad, no se recurre a prácticas punitivas, sino que toda la comunidad coadyuva para que la forma de existencia o el ser humano que ha salido de este equilibrio y armonía vuelva a ellos (...)

Por eso, lo que aparentemente aparece como una 'pena' o un 'castigo' es simplemente una sanción o reprimenda, amonestación, advertencia o llamado de atención para que se mantenga el Ayllukuna Alli Kausay y se pueda llegar al sumak kawsay o el buen vivir que está garantizado en la Constitución Política. Es por eso que en muchos casos al querer equiparar el 'aconsejamiento' o la sanción y advertencias a aquellos que se llaman 'penas' o 'castigos' en el Derecho positivo, se descontextualiza y se interpreta como algo contrario a los derechos humanos o atentatorio de la integridad física de las personas" 3

La Corte Constitucional, pese al prolijo análisis y estudio jurídico-antropológico efectuado por los peritos contratados, dicta un precedente constitucional en el siguiente sentido:

La jurisdicción y competencia para conocer, resolver y sancionar los casos que atenten contra la vida de toda persona, es facultad exclusiva y excluyente del sistema de Derecho Penal Ordinario, aun en los casos en que los presuntos involucrados y los presuntos responsables sean ciudadanos pertenecientes a comunidades, pueblos y nacionalidades indígenas, así los hechos ocurran dentro de una comunidad, pueblo o nacionalidad indígena.

La administración de justicia indígena conserva su jurisdicción para conocer y dar solución a los conflictos internos que se producen entre sus miembros dentro de su ámbito territorial y que afecten sus valores comunitarios ${ }^{4}$.

Con esta sentencia la Corte Constitucional sentó un precedente que contraría el texto constitucional, pues, la Carta Magna no limita el poder jurisdiccional de las autoridades indígenas, sino, todo lo contrario, lo reconoce y garantiza. Por lo tanto, si la misma Constitución no limita el ámbito jurisdiccional de los pueblos indígenas, para conocer y resolver "únicamente" sus conflictos internos en relación con sus valores comunitarios, no es dable, ni aceptable, en un Estado constitucional de derechos y justicia, que el máximo órgano de control e interpretación de

\footnotetext{
${ }^{3}$ Corte Constitucional del Ecuador, sentencia N${ }^{\circ} 113-14-S E P-C C$, de fecha 30 de julio de 2014.
}

${ }^{4}$ Corte Constitucional del Ecuador, sentencia N${ }^{\circ} 113-14-S E P-C C$, de fecha 30 de julio de 2014. 
la Constitución (Corte Constitucional) dicte un precedente a través del cual, restringa y limita derechos fundamentales de los pueblos y nacionalidades indígenas, en este caso, el derecho a su autodeterminación y a resolver sus conflictos con base a su derecho propio.

\section{Conclusiones}

El contenido del derecho indígena responde a un proceso de identidad cultural, construido durante miles de años, sobre la base de su cosmovisión, esto es, de la menara en que ellos entienden e interpretan el mundo. Tiene un profundo sentido humanista de respeto entre ellos, pero, además, de convivencia armónica con la naturaleza, lugar donde empieza y termina la vida.

El reconocimiento por parte del Estado del derecho indígena no ha sido pacífico, todo lo contrario, se ha ido construyendo a través de la lucha de sus pueblos, incluso con derramamiento de sangre, pues, muchos de sus líderes han sido victimados en el desarrollo de tal proceso.

La jurisdicción indígena y sus procedimientos forman parte de la identidad cultural de los pueblos y nacionalidades indígenas, cuyas prácticas se realizan cientos de años antes de la llegada de los españoles a continente americano. Por ende, los homicidios, asesinatos y demás "infracciones graves", siempre han sido resueltos en base a sus costumbres y derecho consuetudinario.

La justicia ordinaria y la justicia indígena pueden convivir armónicamente en nuestra sociedad, siempre y cuando el Estado establezca las condiciones para que ello suceda. A nuestro entender, tales condiciones tienen que ver, fundamentalmente, con el respeto irrestricto a la decisión de sus autoridades. Recordemos que las resoluciones de la justicia indígena se realizan con la participación activa de sus integrantes, es decir, no son decisiones arbitrarias que responden al criterio de una sola persona, todo lo contrario, se adoptan en consenso.

La cultura occidental debería aprender de la cosmovisión indígena y su derecho propio, pues, los procedimientos son más eficaces, son orales, devuelven la paz y tranquilidad a la colectividad, no existe cárcel para los infractores, pero ello no significa de modo alguno que exista impunidad o evasión de responsabilidad.

\section{Bibliografía}

Acosta, Alberto y Martínez, Esperanza. (2009). El Estado plurinacional puerta abierta para una sociedad democrática. En Plurinacionalidad: Democracia en la diversidad. Ediciones Abya-Yala. Quito, Ecuador.

Basadre, Jorge. (1984). Historia del Derecho peruano. Ediciones Gráficas S.A. Segunda edición. Lima, Perú.

Constitución de la República del Ecuador. (2008).

Corte Constitucional del Ecuador (2014). , sentencia $\mathrm{N}^{\circ} 113-14-\mathrm{SEP}-\mathrm{CC}$, de fecha 30 de julio de 2014. 
Cruz Rueda, Eliza. (2008). Principios Generales del Derecho Indígena. En Hacia sistemas jurídicos plurales. Konrad Adenauer Stiftung. Bogotá. Colombia. P.31

Cruz Rueda, Eliza. (2008). Principios Generales del Derecho Indígena. En Hacia sistemas jurídicos plurales. Konrad Adenauer Stiftung. Bogotá. Colombia.

Díaz, Elías. (1985). Estado de Derecho y Sociedad Democrática. Taurus. Madrid, España.

Hernández Terán, Miguel. (2001). Justicia Indígena, Derechos Humanos y Pluralismo Jurídico. Análisis, doctrina y jurisprudencia. Corporación de Estudios y Publicaciones. Quito, Ecuador.

INDESIC. (2001). Instituto para el Desarrollo Social y de las Investigaciones Científicas y Fundación Hanss Seidel. Quito, Ecuador, 2001, p. 88 y 89.

Instituto Ecuatoriano de Estadísticas y Censos (INEC) http://www.ecuadorencifras.gob.ec/resultados/ fecha de consulta 14/02/2017.

(2017).

$$
\text { Ecuatoriano }
$$

Instituto Ecuatoriano de Estadísticas y Censos (INEC) http://www.ecuadorencifras.gob.ec/resultados/ fecha de consulta 14/02/2017.

Macas, Luis. (2002). La Lucha del Movimiento Indígena en Ecuador. Publicación mensual del Instituto Científico de Culturas Indígenas. Año 4. N³7. 2002. Recuperado en: http://icci.nativeweb.org/boletin/37/macas.htm

Masapanta Gallegos, Christian. (2015). Acción Extraordinaria de Protección contra Decisiones de la Justicia Indígena. Corporación de Estudios y Publicaciones. Quito, Ecuador. P. 6.

Rabinovich-Berkman, Ricardo. (2016). Historia del Derecho. Editora jurídica Cevallos. Quito, Ecuador.

Reig, José y Larrea, Juan. (2000). Manual de Historia del Derecho en Ecuador. Corporación de Estudios y Publicaciones. Quito, Ecuador.

Rosillo Martínez, Alejandro. (2012). La Tradición Hispanoamericana de Derechos Humanos. Centro de Estudios y Difusión del Derecho Constitucional. Quito, Ecuador.

Santa María, Rafael. (2012). Dignidad Humana y "Nuevos Derechos": una confrontación en el Derecho peruano. Palestra. Chiclayo, Perú.

SIDENPE. (2017). Recuperado en: http://www.siise.gob.ec/siiseweb/PageWebs/Marco\%20Conceptual/macsdp_listan.htm. 